\title{
Uric Acid as a Biomarker of Metabolic Syndrome in Sudanese Adults
}

\section{Ismail EM ${ }^{1}$, Elbadawi $\mathrm{N}^{2 *}$ and Hassan $\mathrm{D}^{3}$}

${ }^{1}$ Associate Professor of Biochemistry, Assistant dean for Quality and Development, AlNeelain University, AlNeelain University, Sudan

${ }^{2}$ Associate Professor, Department of Biochemistry, Shaqra University, KSA

${ }^{3}$ Associate Professor of Biochemistry, Director/Central Laboratory, Ministry of Higher

Education and Scientific research, Sudan

*Corresponding author: Nour Eldaim Elnoman Elbadawi, Associate Professor, Department of Biochemistry, College of Medicine, Shaqra University, KSA-Shaqra, Tel: 00966543808051 ; Email: noureldaim@hotmail.com

\section{Abstract}

Serum uric acid (SUA) is considered as a component and a marker of metabolic syndrome (MetS). Our aim is to investigate the prevalence of hyperuricemia and its relationships to MetS and its components such as hypertension (HTN), glucose intolerance, obesity and hyperlipidemia among Sudanese population.

Method: This is a descriptive cross sectional study, held in Khartoum State, Sudan. The study was performed with a sample of 219, adults, attending the clinics set by the Sudanese Society of Hypertension on the occasion of the International day of hypertension from 2015 to 2016. Using World Health Organization WHO) definition, direct measurements were obtained for metabolic syndrome components; anthropometric screenings included: measurement of height, weight, and body mass index (BMI). The clinical and biochemical screenings included: measurement of blood pressure (BP) and determination of fasting lipid profile, glucose concentrations and serum uric acid.

Results: This study enrolled 219 participants aged 18 - 75 year. MetS prevalence was $25.1 \%$ among the entire group, (41.8\% males, \& $58.1 \%$ females). Hyperurecemia was detected in (41.1\%) among the study group (52.2 \% males, $47.7 \%$ females $\mathrm{P}>0.05$ ). $60 \%$ of the MetS cases were found to suffer from Hyperurecemia. $(\mathrm{P}<0.01)$. In the overall group, SUA concentrations ranged from $3.0-12.0 \mathrm{mg} / \mathrm{dl}$, with a mean of $6.0 \pm 1.7 \mathrm{mg} / \mathrm{dl}$.

Hyperurecemia was significantly positively correlated with BMI $(\mathrm{r}=.226, \mathrm{p}=.001)$, triglyceride $(\mathrm{r}=.247, \mathrm{p}=.000)$, and cholesterol ( $\mathrm{r}=.184, \mathrm{p}=.007)$.

Conclusion: Hyperuricemia was highly prevalent among Sudanese population. Additionally, for those with hyperuricemia, the odds ratios $(95 \% \mathrm{CI}$ ) for metabolic syndrome were 3.61 (95\% CI, .591 .749) and for fasting blood glucose 0.478 (95\% CI, .392 .593). SUA can be considered as a better predictor of metabolic syndrome than fasting glucose, though not as good as hyperlipidemia and obesity.

Keywords: Hyperuricemia; Metabolic syndrome; Hypertension; Uric acid 


\section{International Journal of Biochemistry \& Physiology}

Abbreviations: SUA: Serum uric acid; MetS: Metabolic Syndrome; HTN: Hypertension; BMI: Body Mass Index; BP: Blood Pressure; WHO: World Health Organization; RAAS: Rennin-angiotensin Aldosterone System; SSH: Sudanese Society of Hypertension; SBP: Systolic Blood Pressure; HDL: High Density Lipoprotein.

\section{Introduction}

Serum uric acid (SUA) is the end metabolite product of purine degradation [1], and is the most abundant antioxidant in human plasma [2], as it protects against freeradical oxidative damage [3].

Serum uric acid is often elevated in subjects with Metabolic Syndrome (MetS) as a compensatory mechanism to counteract the increased oxidative stress under the circumstances of metabolic syndrome [4]. The associations between hyperuricemia and MetS components such as obesity, raised BP, hyperlipidemia, and glucose intolerance have been reported in many previous studies [5-7]. So, hyperuricemia is considered by some investigators to be a component and a marker of metabolic syndrome $[8,9]$. Prevalence of metabolic syndrome has recently increased in developing countries. It has been estimated that approximately $10 \%-30 \%$ of the world's adult population suffer from MetS [10]. All these studies granted that the prevalence of the MetS is highly age dependent and the highest prevalence among women compared to men [10]. In Sudan the Prevalence rates of metabolic syndrome using WHO criteria was 6.1 $\%$ among young adults [11]. Hyperuricemia was reported in $25-40 \%$ of untreated hypertensive and $75 \%$ of malignant hypertensive patients [12]. Hyperuricemia causes hypertension through pathways that are involved in reduction of nitric oxide synthase in the macula densa of the kidney, stimulation of rennin-angiotensin aldosterone system (RAAS), and reduction of renal perfusion. Importantly, each of these effects was ameliorated by uric acid lowering drugs [13]. Uric acid is a product of glucose metabolism that is filtered by glomeruli and reabsorbed by the proximal tubule. Greater serum concentrations of insulin cause higher renal reabsorption of uric acid, and increasing serum concentrations of uric acid [14]. However the relation between uric acid and blood glucose is controversial $[15,16]$.

\section{Methodology}

This is a descriptive cross sectional study carried out in Umbada area, Khartoum State, Sudan, in Sudanese adults attending the clinics set by the Sudanese Society of Hypertension (SSH) on the occasion of the International Day of Hypertension in the period from January 2015 to February 2016. Total number of the study group was 219 , (111 males and 108 females). Informed consent was given verbally by the respondents after research objectives were clearly discussed with them. Random selection was the sampling technique adopted for this study.

The prevalence of MetS was assessed on the basis of the WHO criteria [17]. It comprises diabetes mellitus or an impaired fasting glucose of $\geq 110 \mathrm{mg} / \mathrm{dl}$, in addition to two of the following features:

- $\mathrm{BMI}>30 \mathrm{Kg} / \mathrm{m}^{2}$.

- Hypertriglyceridemia with $\mathrm{TG}>150 \mathrm{mg} / \mathrm{dl}$;

- HDL-C $<35 \mathrm{mg} / \mathrm{dl}$ for men and $<39 \mathrm{mg} / \mathrm{dl}$ for women;

- High BP >140/90 mm Hg or documented evidence of anti-hypertensive therapy.

Hyperuricemia is defined as serum uric acid level $\geq 7$ $\mathrm{mg} / \mathrm{dl}$ (in men) or $\geq 6.0 \mathrm{mg} / \mathrm{dl}$ (in women) [18]. Body weight was measured to an accuracy of $0.1 \mathrm{~kg}$ using a standard balance scale manufactured by Microlife ${ }^{\circledR}$, Switzerland. Subjects were barefoot and wearing light indoor clothing. Body height was recorded to the nearest $0.5 \mathrm{~cm}$ using a ruler attached to the wall without shoes. BMI was obtained through body weight $(\mathrm{kg})$ divided by the square of their height (m). The definition of BMI used in this study is the same as the definition of world health organization [17] which is: Underweight $<18.50$, Normal18.50 - 24.99, overweight $\geq 25$ obese $\geq 30$. Blood pressure was measured using sphygmomanometers with subjects seated in a chair with arm at the level of the heart. Standard mercury sphygmomanometer was used with regular adult cuff size. Systolic and diastolic blood pressure was considered as Korotkoff's phases 1 and 5 respectively. The BP was measured again after a 5-min rest and the average BP was used in the analysis. For this study, hypertension was defined as systolic blood pressure (SBP) $\geq 140 \mathrm{mmHg}$, or diastolic blood pressure (DBP) $\geq 90 \mathrm{mmHg}$. Biochemical assessment done using fasting blood samples collected intravenously using $5 \mathrm{ml}$ sterile syringes in anticoagulant-containing sterile containers. Samples were then centrifuged at 3000rpm for 5 minutes and plasma was separated and biochemical parameters were measured using enzymatic colorimetric assay. Samples were analyzed using the same colorimetric device (Jenway bench colorimeter 6051- UK) and the same chemical reagent kit (Bio systems-Germany). Plasma uric acid, glucose, total cholesterol, triglycerides, and high density lipoprotein (HDL), were assayed using 


\section{International Journal of Biochemistry \& Physiology}

spectrophotometric technique and enzymatic endpoint kits from Bio-system Company. LDL concentration calculated using Friedwald formula. SPSS (version 20) was used for analysis of data. t-test was used for comparison of variables of the test group and the control group. Pearson's correlation was used for assessment of correlation between variables. P. value $\leq 0.05$ was considered significant.

\section{Results}

\begin{tabular}{|c|c|c|c|}
\hline & $\begin{array}{c}\text { Normal Serum Urate } \\
\mathrm{N}=129(58.9 \%)\end{array}$ & $\begin{array}{l}\text { Hyperuricemia } \\
\mathrm{N}=90(41.0 \%)\end{array}$ & $P$ value \\
\hline $\mathrm{M} / \mathrm{F}(\mathrm{N})$ & $72 / 84$ & $39 / 24$ & 0.024 \\
\hline $\begin{array}{c}\text { Age } \\
(\text { mean years } \pm \mathrm{SE})\end{array}$ & $49.2 \pm 1.6$ & $49.3 \pm 1.1$ & 0.6 \\
\hline MetS 55 (N \& \%) & $22(40 \%)$ & $33(60 \%)$ & 0 \\
\hline BMI $($ mean \pm SE) & $26.5( \pm .45)$ & $29.3( \pm .73)$ & \\
\hline$\bullet<18$ underweight $(\mathrm{N}=7)(\%)$ & 100 & 0 & \\
\hline -18.1-24.9normal $(\mathrm{N}=69)(\%)$ & 81 & 18.8 & 0.001 \\
\hline - 25-29.9overweight $(\mathrm{N}=84)(\%)$ & 65.4 & 34.5 & \\
\hline$\bullet \geq 30$ obese $(\mathrm{N}=59)(\%)$ & 57.6 & 42.3 & \\
\hline Cholesterol (mean \pm SE) & $204( \pm 4.1)$ & $225( \pm 7.0)$ & 0.007 \\
\hline Triacylglycerol $($ mean \pm SE) & $136( \pm 5.4)$ & $174( \pm 9.3)$ & 0 \\
\hline Fasting blood glucose (mean \pm SE) & $147( \pm 6.0)$ & $129( \pm 7.3)$ & 0.07 \\
\hline Uric acid $($ mean $\pm S E)$ & $5.3( \pm 0.08)$ & $8.3( \pm .14)$ & 0 \\
\hline HDL (mean \pm SE) & $18.5( \pm 0.66)$ & $19.1( \pm 1.5)$ & 0.67 \\
\hline LDL $($ mean \pm SE) & $160.6( \pm 3.9)$ & $166.7( \pm 6.4)$ & 0.8 \\
\hline Systolic BP (mean \pm SE) & $126.7( \pm 1.4)$ & $131.7( \pm 2.3)$ & 0.061 \\
\hline Diastolic BP (mean \pm SE) & $81.7( \pm 13.9)$ & $84.7( \pm 1.6)$ & 0.103 \\
\hline
\end{tabular}

Table 1: General characteristics of the study group classified according to serum uric acid level.

\begin{tabular}{|c|c|c|c|}
\hline & Males (111) & Females (108) & $P$ value \\
\hline $\begin{array}{l}\text { High TG >150 mg/dl } \\
\quad \mathrm{N}=70(31.9 \%)\end{array}$ & $35(31.5 \%)$ & $35(32.4 \%)$ & 0.889 \\
\hline $\begin{array}{l}\text { High FBG } \geq 110 \mathrm{mg} / \mathrm{dl} \\
\mathrm{N}=139(67.3 \%)\end{array}$ & $67(60.3 \%)$ & $72(66.6 \%)$ & 0.333 \\
\hline $\begin{array}{c}\text { Hyperurecemia: } \mathrm{N}=90(41.0 \%) \\
\geq 7 \mathrm{mg} / \mathrm{dl} \text { (in men) } \\
\geq 6.0 \mathrm{mg} / \mathrm{dl} \text { (in women) }\end{array}$ & $46(41.4 \%)$ & $44(40.7 \%)$ & 0.916 \\
\hline $\mathrm{BMI} \geq 30 ; \mathrm{N}=62(28.3 \%)$ & $25(22.5 \%)$ & $37(34.2 \%)$ & 0.05 \\
\hline $\begin{array}{l}\text { Low HDL-C: } \mathrm{N}=185(84.4 \%) \\
\quad<35 \mathrm{mg} / \mathrm{dl} \text { for men } \\
<39 \mathrm{mg} / \mathrm{dl} \text { for women }\end{array}$ & $91(81.9 \%)$ & $94(87.0 \%)$ & 0.302 \\
\hline High Systolic BP >140mm N=113 (51.5\%) & $59(53.1 \%)$ & $54(50 \%)$ & 0.641 \\
\hline $\begin{array}{c}\text { High Diastolic BP >90 mm } \\
\mathrm{N}=89(40.6 \%)\end{array}$ & $48(43.2 \%)$ & $41(37.9 \%)$ & 0.426 \\
\hline $\begin{array}{c}\text { High } \mathrm{BP}>140 / 90 \mathrm{~mm} \mathrm{Hg} \\
\mathrm{N}=54(24.6 \%)\end{array}$ & $28(25.2 \%)$ & $26(24.0 \%)$ & 0.843 \\
\hline
\end{tabular}

Table 2: The percentage of abnormal/high metabolic syndrome components categorized by gender. 


\section{International Journal of Biochemistry \& Physiology}

\begin{tabular}{|c|c|c|c|c|c|c|}
\hline & BMI & FBG & TG & cholesterol & SBP & DBP \\
\hline Hyperurecemia & 0.226 & -0.122 & 0.247 & 0.184 & 0.128 & 0.112 \\
\hline Sig. (2-tailed) & 0.001 & 0.077 & 0 & 0.007 & 0.061 & 0.103 \\
\hline BMI & & -0.096 & 0.192 & 0.021 & 0.307 & 0.366 \\
\hline Sig. (2-tailed) & & 0.17 & 0.006 & 0.763 & 0 & 0 \\
\hline FBG & & & 0.001 & 0.125 & -0.049 & -0.048 \\
\hline Sig. (2-tailed) & & & 0.988 & 0.068 & 0.478 & 0.486 \\
\hline TG & \multirow{3}{*}{ Sig. (2-tailed) } & & & 0.381 & 0.193 & 0.135 \\
\hline cholesterol & & & & & 0.005 & 0.05 \\
\hline Sig. (2-tailed) & & & & 0.006 & -0.046 \\
\hline SBP & & & & & 0.931 & 0.5 \\
\hline Sig. (2-tailed) & & & & & 0.718 \\
\hline
\end{tabular}

Table 3: Correlation between hyperurecemia and metabolic syndrome components.

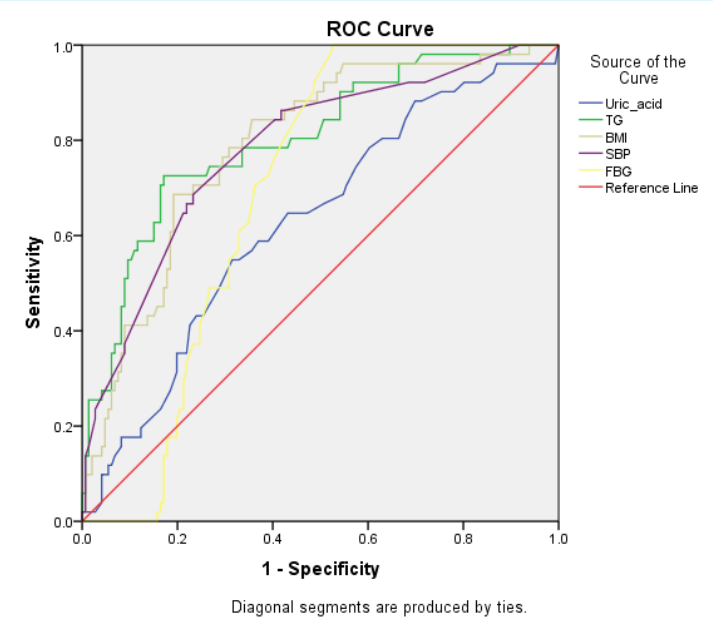

Figure 1: ROC curve of TG, SBP, cholesterol, BMI, FBG and SUA in relation to the presence of MetS.

\section{Discussion}

In the present study, we assessed the association between hyperurecemia and different parameters of metabolic syndrome in a population of Sudanese adults. Our study comprised 219 adults, 111 male and 108 female with male to female ratio 1: 1 , their mean age was 49.3 years $( \pm$ SD 13.7) ranging between 18 and 75 years.

Using WHO criteria MetS was detected among 55 $(25 \%)$ of our study group. In relation to other studies the prevalence of metabolic syndrome was found to be $21 \%$, $24.3 \%, 33.9 \%, 34.7 \%, 36.3 \%, 37.0 \%$ among Saudi ,Tunisia, Turkish Iranian, Jordanian and Palestinian adults respectively [19].
The high prevalence of MetS among our study group may be related to high exposure to westernized foods and eating habits together with lower socioeconomic status and poorer health awareness [19]. The gender differences in prevalence of MetS have been found in several studies $[20,21]$. Our results showed that MetS was more prevalent among women (58\%) than men $(41.2 \%)$. It might be due to different-cut-off points set as criteria for MetS finding or related to the higher incidence of-obesity among women [22]. In our population hyperuricemia was detected in $41.0 \%$ which is considered high in relation to Brazilian [23], Chinese [24], and Kuwait populations [25], $13.2 \%, 13.7 \%$ and $24.9 \%$ respectively. In Sudanese, hyperurecemia may be due to overproduction of uric acid caused by increased consumption of carbohydrate as it represents $65.7 \%$ of average daily intake of the Sudanese meals [26]. This high intake of fructose and sucrose may explain the rise in obesity as $53.9 \%$ of the Sudanese population are considered as overweight or obese [27]. In our group, overweight and obesity were detected in $65.8 \%$. The high prevalence of obesity may be explained by the accelerated urbanization that has been accompanied by nutrition transition, resulting in lower levels of physical activity, and the exchange of traditional foods high in complex carbohydrates for new foods high in refined carbohydrates [28].

Among the hyperurecemic group, MetS was detected among 60\%. In agreement with our results, hyperuricemia was found to be strongly associated with metabolic syndrome components such as BMI, triacylglycerol and cholesterol [29]. Hyperurecemia may be partially responsible for inflammatory imbalances in adipose tissues that lead to low-grade inflammation and insulin resistance [30]. Also metabolic syndrome may cause nucleic acid metabolism abnormalities, which 


\section{International Journal of Biochemistry \& Physiology}

stimulate adenosine monophosphate (AMP) deaminase that produce uric acid which promotes fat storage and insulin resistance [31].

Uric acid is considered as one of the major factors that raises blood pressure by stimulating intracellular oxidative stress and activation of NADPH oxidase in the cytosol and mitochondria [32,33]. $24.7 \%$ of our patients were hypertensive; hyperurecemia was detected among $48.1 \%$ of the cases.

Hyperuricemia may induce insulin resistance causing vasodilatation and increase blood flow that interfere with the action of nitric oxide, which facilitates glucose absorption [34], other results suggest that hyperurecemia is caused by hyperinsulinemia acting on the renal tubules to facilitate the reabsorption of uric acid $[35,36]$. In contrast to these studies we found a non significant negative correlation between fasting blood glucose $(P=$ 061) and serum uric acid.

In conclusion, the findings of this study strongly emphasize that, hyperuricemia is highly prevalent among Sudanese population.SUA can be considered as a better predictor of metabolic syndrome than fasting glucose, though not as good as hyperlipidaemia and obesity.

\section{Ethical Consideration}

Written informed consent was obtained from the respondents before entry into the study according to the guidelines of the Ethical Committee of college of medicine, Alneelain University.

\section{References}

1. Zhang C, Liu R, Yuan J, Cui J, Hu F, Weixian et al. (2016) Gender-related differences in the association between serum uric acid and left ventricular mass index in patients with obstructive hypertrophic cardiomyopathy. Biol Sex Differ 7: 22.

2. Ames BN, Cathcart R, Schwiers E, Hochstein P (1981) Uric acid provides an antioxidant defense in humans against oxidant- and radical-caused aging and cancer: a hypothesis. Proc Natl Acad Sci USA 78(11): 68586862.

3. Fabbrini E, Serafini M, Baric IC, Hazen SL, Klein S (2014) Effect of plasma uric acid on antioxidant capacity, oxidative stress, and insulin sensitivity in obese subjects. Diabetes. 63(3): 976-981.

4. Hansel B, Giral P, Nobecourt E, Chantepie S, Bruckert E (2004) Metabolic syndrome is associated with elevated oxidative stress and dysfunctional dense high-density lipoprotein particles displaying impaired santioxidative activity. J Clin Endocrinol Metab 89(10): 4963-4971.

5. Wilson PW, D'Agostino RB, Parise H, Sullivan L, Meigs JB (2005) Metabolic syndrome as a precursor of cardiovascular disease and type 2 diabetes mellitus. Circulation 112: 3066-3072.

6. McNeill AM, Katz R, Girman CJ, Rosamond WD, Wagenknecht LE, et al. (2006) Metabolic syndrome and cardiovascular disease in older people: The cardiovascular health study. J Am Geriatr Soc 54: 1317-1324.

7. Lorenzo C, Williams K, Hunt KJ, Haffner SM (2007) The National Cholesterol Education Program et al. Adult Treatment Panel III, International Diabetes Federation, and World Health Organization definitions of the metabolic syndrome as predictors of incident cardiovascular disease and diabetes. Diabetes Care 30(1): 8-13.

8. Sung KC, Kim BJ, Kim BS, Kang JH, Lee MH, et al. (2004) In normoglycemic Koreans, insulin resistance and adipocity are independently correlated with high blood pressure. Circ J 68(10): 898-902.

9. Ishizaka N, Ishizaka Y, Toda E, Nagai R, Yamakado M (2005) Association Between Serum Uric Acid, Metabolic Syndrome, and Carotid Atherosclerosisin Japanese Individuals. Arterioscler Thromb Vasc Biol 25(5): 1038-1044.

10. Mulè G, Calcaterra I, Nardi E, Cerasola G, Cottone S (2014) Metabolic syndrome in hypertensive patients: An unholy Alliance. World J Cardiol 6(9): 890-907.

11. Sabir FM, Hassan DA, Elamin MI (2016) Prevalence of Metabolic Syndrome among Young Sudanese University Students Using Three Different Criteria of WHO, IDF and NCEP-ATP III. Pediatr Neonatal Nurs Open Access 2(2).

12. Alper AB Jr, Chen W, Yau L, Srinivasan SR, Berenson GS, et al. (2005) Childhood uric acid predicts adult 


\section{International Journal of Biochemistry \& Physiology}

blood pressure - The Bogalusa Heart Study. Hypertension 45: 34-38.

13. Soltani Z, Rasheed K, Kapusta DR, Reisin E (2013) Potential Role of Uric Acid in Metabolic Syndrome, Hypertension, Kidney Injury, and Cardiovascular Diseases: Is It Time for Reappraisal? Curr Hypertens Rep 15(3): 175-181.

14. Muscelli E, Natali A, Bianchi S, Bigazzi R, Galvan AQ, et al. (1996) Effect of insulin on renal sodium and uric acid handling in essential hypertension. Am J Hypertens 9(8): 746-752.

15. Choi HK, Ford ES (2008) Haemoglobin A1c, fasting glucose, serum C-peptide and insulin resistance in relation to serum uric acid levels-the Third National Health and Nutrition Examination Survey. Rheumatology (Oxford) 47(5): 713-717.

16. Rodríguez G, Soriano LC, Choi HK (2010) Impact of diabetes against the future risk of developing gout. Ann Rheum Dis 69(12): 2090-2094.

17. World Health Organization (2007) "Definition, diagnosis and classification of diabetes mellitus and its complications: Report of a WHO Consultation. Part 1. Diagnosis and classification of diabetes mellitus".

18. Hochberg MC, Smolen JS, Weinblatt ME, Weisman MH (2003) Rheumatology. $3^{\text {rd }}$ (Edn.), Mosby, New York.

19. El Bilbeisi AH, Shab-Bidar S, Jackson D, Djafarian K (2017) The Prevalence of Metabolic Syndrome and Its Related Factors among Adults in Palestine: A MetaAnalysis. Ethiop J Health Sci 27(1): 77-84.

20. Bouguerra R, Alberti H, Smida H, Salem L, Rayana C, et al. (2007) Waist circumference cut-off points for identification of abdominal obesity among the tunisian adult population. Diabetes Obes Metab 9(6): 859-868.

21. Bahijri SM, Al Raddadi RM (2013) The importance of local criteria in the diagnosis of metabolic syndrome in Saudi Arabia. Ther Adv Endocrinol Metab 4(2): 5159.

22. Beigh SH, Jain S (2012) Prevalence of metabolic syndrome and gender differences. Bioinformation 8(13): 613-616.

23. Rodrigues SL, Baldo MP, Capingana $\mathrm{P}$, Magalhães $\mathrm{P}$, Dantas EM, et al. (2011) Gender Distribution of Serum
Uric Acid and Cardiovascular Risk Factors: Population Based Study. Arq Bras Cardiol 98(1): 13-21.

24. Qiu L, Cheng XQ, Wu J, Liu JT, Xu T, et al. (2013) Prevalence of hyperuricemia and its related risk factors in healthy adults from Northern and Northeastern Chinese provinces. BMC Public 13: 664.

25. Al-Meshaweh AF, Jafar Y, Asem M, Akanji AO (2012) Determinants of Blood Uric Acid Levels in a Dyslipidemic Arab Population. Med Princ Pract 21: 209-216.

26. Fifth Sudan population and housing census (2008) Priority results.. Available from Sudan central bureau of food and nutrition security assessment in Sudan analysis of 2009 national baseline household survey.

27. Wise approach to surveillance (STEPS).

28. Jaffe A, Giveon S, Wulffhart L, Oberman B, Baidousi M, et al. (2017) Adult Arabs have higher risk for diabetes mellitus than Jews in Israel. PLoS One 12(5): $\mathrm{e} 0176661$.

29. Chen LY, Zhu WH, Chen ZW, Dai HL, Ren JJ, et al. (2007) Relationship between hyperuricemia and metabolic syndrome. J Zhejiang Univ Sci B 8(8): 593598.

30. Li LX, Dong XH, Li MF, Zhang R, Li TT, et al. (2015) Serum uric acid levels are associated with hypertension and metabolic syndrome but not atherosclerosis in Chinese in patients with type 2 diabetes. J Hypertens 33(3): 482-490.

31. Kanbay M, Jensen T, Solak Y, Le M, Roncal-Jimenez C, et al. (2016) Uric acid in metabolic syndrome: From an innocent bystander to a central player. Eur J Intern Med 29: 3-8.

32. Sautin YY, Nakagawa T, Zharikov S, Johnson RJ (2007) Adverse effects of the classic antioxidant uric acid in adipocytes: NADPH oxidase-mediated oxidative/nitrosative stress. Am J Physiol Cell Physiol 293(2): C584-C596.

33. Costa A, Iguala I, Bedini J, Quinto L, Conget I (2002) Uric acid concentration in subjects at risk of type 2 diabetes mellitus: Relationship to components of the metabolic syndrome. Metabolism 51(3): 372-375. 


\section{International Journal of Biochemistry \& Physiology}

34. Khosla UM, Zharikov S, Finch JL, Nakagawa T, Roncal C, et al. (2005) Hyperuricemia induces endothelial dysfunction. Kidney Int 25: 1739-1742.

35. Lee D, Choi WJ, Oh JS, Yi MK, Han SW (2013) The Relevance of Hyperuricemia and Metabolic Syndrome and the Effect of Blood Lead Level on Uric Acid
Concentration in Steelmaking Workers. Ann Occup Environ Med 25(1): 27.

36. Yoo TW, Sung KC, Shin HS, Kim BJ, Kim BS, et al. (2005) Relationship between serum uric acid concentration and insulin resistance and metabolic syndrome. Circ J 69(8): 928-933. 